\title{
Haemostatic activity of butanolic extracts of Lamium album and Lamium purpureum aerial parts
}

\author{
CORINA BUBUEANU ${ }^{1 *}$ \\ RASIT IUKSEL ${ }^{2}$ \\ MINERVA PANTELI ${ }^{2}$ \\ ${ }^{1}$ Department of Pharmaceutical \\ Biotechnology \\ National Institute \\ for Chemical-Pharmaceutical RED \\ (ICCF-Bucharest) \\ Bucharest, Romania \\ ${ }^{2}$ Department of Pharmacology \\ National Institute \\ for Chemical-Pharmaceutical RED \\ (ICCF-Bucharest) \\ Bucharest, Romania
}

Accepted December 28, 2018

Published online January 21, 2019

\begin{abstract}
Lamium album and Lamium purpureum are species belonging to the genus Lamium. Aerial parts of the two species and roots of Lamium album have applications in human and veterinary traditional medicine. Haemostatic properties of butanolic extracts of Lamium species were investigated by two experimental models in Wistar rats: haemostatic test by tail bleeding time determination and acenocoumarolcarrageenan test. Results of the haemostatic test by tail bleeding determination demonstrated haemostatic activity of both extracts. In the acenocoumarol-carrageenan test, only the Lamium album extract showed haemostatic activity, comparable to that of vitamin $\mathrm{K}$. Based on the qualitative chemical data on iridoid glycosides (HPTLC), 8 -acetylshanzhiside methyl ester might be assumed to be responsible for haemostatic activity. Based on the acute toxicity test, none of the extracts showed toxicity.
\end{abstract}

Keywords: Lamium album, Lamium purpureum, aerial parts, butanolic extract, haemostatic activity, toxicity

A large number of drugs that lead to improvement of human health and prolong life expectancy have been discovered lately. At the same time, new drugs have a considerable number of adverse effects. Today, more and more scientists are turning to medicinal plants, discovering natural chemical compounds with specific actions and mechanisms of performance.

Genus Lamium, which comprises about 40 species distributed in Europe, Asia and Africa, is less studied and much less utilized compared to other members of the Lamiaceae family to which it belongs (1). Lamium album and Lamium purpureum are species belonging to the genus Lamium. Aerial parts of the two species and roots of Lamium album have applications in human and veterinary traditional medicine; they possess diuretic, antiinflammatory, anti-diarrheal, astringent, expectorant, vasoconstrictor, antirheumatic, haemostatic and emollient properties (2). Lamium album is used in human medicine internally in leucorrhea, dysmenorrhea, prostate hypertrophy or inflammation, diarrhea, bronchitis, menopausal nervous state in women, insomnia, convulsive cough and

\footnotetext{
*Correspondence, e-mail: corina.bubueanu@yahoo.com
} 
externally in abscesses, tumors, varicose veins, ulcers, swellings caused by gout. Aerial parts of Lamium purpureum possess antirheumatic, astringent and emollient properties. Empirically, the plant is used to treat epilepsy, rheumatism, abscesses and wounds (2).

As regards chemical composition, literature data indicate the presence of iridoid glycosides as main components (3), as well as benzoxazinoids, polyphenolic compounds, amino acids $(4,5)$, phenylethanoid and phenylpropanoid glycosides (1), phytoecdysteroids (6) and fatty and volatile oils (7) in both species of the genus Lamium. Lamium album and Lamium purpureum show notable differences in the qualitative and quantitative chemical composition of polyphenolic compounds (9).

In this paper, we present an investigation on the qualitative chemical composition of iridoid glycosides in butanolic extracts from Lamium album and Lamium purpureum aerial parts and their haemostatic properties, as well as their lack of toxicity.

\section{EXPERIMENTAL}

\section{Plant material and extracts}

Lamium album L. and Lamium purpureum L. aerial parts were obtained from the Fundulea Research Station (Romania) and dried and ground to fine powder. Voucher specimens are deposited in ICCF - Bucharest, Plant Material Storing Room.

Extracts were obtained by extraction with distilled water $\left(\mathrm{pH} 9.5\right.$ with $\mathrm{CaCO}_{3}$, vegetal material/solvent ratio $1: 15, \mathrm{~m} / \mathrm{V}$ ) in a water bath at $50{ }^{\circ} \mathrm{C}$ for 2 hours, under continuous stirring. After filtration, the solution was centrifuged at $3000 \mathrm{rpm}$ for 30 minutes. The resulting solution was concentrated to half its volume, under reduced pressure at $50{ }^{\circ} \mathrm{C}$, with a rotary evaporator and extracted 5 times with butanol (water extract/butanol ratio, $1: 2, V / V)$. The butanolic solution obtained from liquid-liquid extraction was concentrated under reduced pressure at $50{ }^{\circ} \mathrm{C}$ to a thick extract.

\section{HPTLC analysis of iridoids}

Qualitative analyses of iridoids were performed according to TLC Atlas - Plant Drug Analyses (10). Butanolic extracts were dissolved in HPLC grade methanol $(50 \%, V / V)$ to obtain a $1 \%(\mathrm{~m} / \mathrm{V})$ solution. Reference substances, 8-acetyl shanzhiside methyl ester and shanzhiside methyl ester (PhytoLab, Germany) were also dissolved in methanol to prepare $1 \%(\mathrm{~m} / \mathrm{V})$ solutions. Then, $0.8-3 \mu \mathrm{L}$ of the samples and $0.8-2.8 \mu \mathrm{L}$ of reference substances were loaded as 10-mm bands onto $20 \times 10 \mathrm{~cm}$ TLC plates (Silica gel 60F254, CAMAG LINOMAT 5 instrument, Camag, Switzerland). The mobile phase was chloroform/methanol/water (60:40:4) $(V / V V)$. After development, plates were dried and derivatised with sulphuric acid vanillin reagent at $100{ }^{\circ} \mathrm{C}$. Fingerprints were evaluated in fluorescence mode at $254 \mathrm{~nm}$ (after derivatisation) with the aid of WinCats and VideoScan software.

\section{Experimental animals}

Wistar rats and NRMI mice of both sexes were provided by the Institute Cantacuzino - Baneasa Branch (Romania) and used in in vivo experimental studies. All experiments complied with the regulations issued by FELASA (Federation of European Laboratory Animal Science Associations) and ARSAL (Romanian Association for Laboratory Animal 
Science) and were approved by the ethics committees of the National Institute for Chemical-Pharmaceutical R\&D (ICCF-Bucharest, Romania) for animal experimentation.

Animals were housed under standard environmental conditions, at $22 \pm 2{ }^{\circ} \mathrm{C}$, relative humidity 50-60\%, under a 12-h dark-light cycle with free access to water and standard pellet diet. Rats were kept in the experimental facility for 7 days to get acclimated prior to dosing. Animals were deprived of food 12 hours prior to dosing.

\section{Acute toxicity test}

Male and female NRMI mice, weighing 18-20 g, were used. Extracts were administered orally by intragastric gavage as a $28 \mathrm{~g}$ per $100 \mathrm{~mL}$ aqueous suspension (prepared with Tween $80,2 \%$ ) of the test sample in a dose of $7.00 \mathrm{mg} \mathrm{kg}^{-1}$ body mass, in a volume of $0.5 \mathrm{~mL}$ per $20 \mathrm{~g} \mathrm{bm}$ (maximum for the species). After administration of the suspension, the animals were monitored each hour within the first 8 hours, and at least twice a day for 14 days. On the last day of the experiment, the animals were euthanized observing the current rules for necropsy examination.

\section{Haemostatic test by tail bleeding time determination}

Male Wistar rats weighing 270-350 g were divided into three groups $(n=6)$. The control group (group 1) received distilled water, while groups 2 and 3 were administered Lamium purpureum extract and Lamium album extract, resp. The extract was administered orally, by intragastric gavage, as $1 \%$ suspension (prepared with Tween 80, $2 \%$ in distilled water), corresponding to a $50 \mathrm{mg} \mathrm{kg}^{-1} \mathrm{bm}$ dose. Lamium purpureum extract and Lamium album extract suspensions and distilled water were administrated in a volume of $0.5 \mathrm{~mL}$ per $100 \mathrm{~g} \mathrm{bm}$, once a day for four consecutive days. On the fourth day, the haemostatic activity was evaluated by tail bleeding time determination after applying a scalpel incision onto animal tail. Before the incision, the animals were sedated with diazepam (Terapia SA., Romania) $2.5 \mathrm{mg} \mathrm{kg}^{-1} \mathrm{bm}$ administered i.m. Tail skin was cleaned and disinfected, then an incision of $2 \mathrm{~mm}$ depth was made in the proximal region with a sterile scalpel once the timer started. The cut wound was dabbed with filter paper every $15 \mathrm{~s}$ until the bleeding stopped. Time from the incision until bleeding stopped was recorded as bleeding time (11).

\section{Acenocoumarol carrageenan test}

In this study, Wistar rats of both sexes, weighing 130-180 g, were used. Animals received a single subcutaneous dose of carrageenan (Sigma-Aldrich, USA) into the top of the skull, followed by acenocoumarol (Trombostop $2 \mathrm{mg}$ tablets, Terapia Ranbaxy, Romania) administered orally for 3 days. For each animal with no haemostatic treatment, an extensive haematoma was observed at the carrageenan injection site on day four. Combined administration of an anticoagulant and carrageenan is a suitable means of inducing haemorrhagic necrosis in rats. Animals that received vitamin $\mathrm{K}$ before the subcutaneous injection of carageenan followed by acenocoumarol for 3 days had no haematoma at the carrageenan injection site.

Animals were divided into 10 groups ( $n=12,6$ males and 6 females) for every test sample. On day one, the animals were treated as follows: the positive control group (group 1) was treated with $1.35 \mathrm{mg} \mathrm{kg}^{-1} \mathrm{bm}$ vitamin $\mathrm{K}$ per os ( $2 \mathrm{~mL}$ per $200 \mathrm{~g} \mathrm{bm}$ ); groups $2-5$ were 
C. Bubueanu et al.: Haemostatic activity of butanolic extracts of Lamium album and Lamium purpureum aerial parts, Acta Pharm. 69 (2019) 443-449.

treated with 1, 2, 4 and $10 \%$ Lamium album extract, resp., (2 mL per $200 \mathrm{~g} \mathrm{bm);} \mathrm{groups} \mathrm{6-9}$ were treated with 1, 2, and $10 \%$ Lamium purpureum extract, resp. (2 mL per $200 \mathrm{~g} \mathrm{bm})$; the negative control group (group 10) received distilled water (2 $\mathrm{mL}$ per $200 \mathrm{~g} \mathrm{bm}$ ).

On day two, the animals were sedated with diazepam $2.5 \mathrm{mg} \mathrm{kg}^{-1} \mathrm{bm}$ administered i.m. Rats were epilated in the scalp region and then injected subcutaneously with carrageenan $1 \%, 0.05 \mathrm{~mL}$ per scalp region/animal. On the following 3 days, all animals received acenocoumarol orally, $0.72 \mathrm{mg} \mathrm{kg}^{-1}$ as a daily dose (12). On the fifth day of the experiment, animals were euthanized according to the effective rules (13) and a transverse biretroauricular incision to the bone structures was made. The resulting flap was tractioned posteriorly in order to examine and reveal possible haematoma induced by carrageenan.

A presumptive haematoma prevention index was calculated.

\section{Data analysis}

The results were expressed as mean \pm SD. The data were analysed using Student's t-test.

\section{RESULTS AND DISCUSSION}

TLC profiles of the butanolic extracts of Lamium album and Lamium purpureum are shown in Fig. 1 and compared to reference substances, shanzhiside methyl ester and

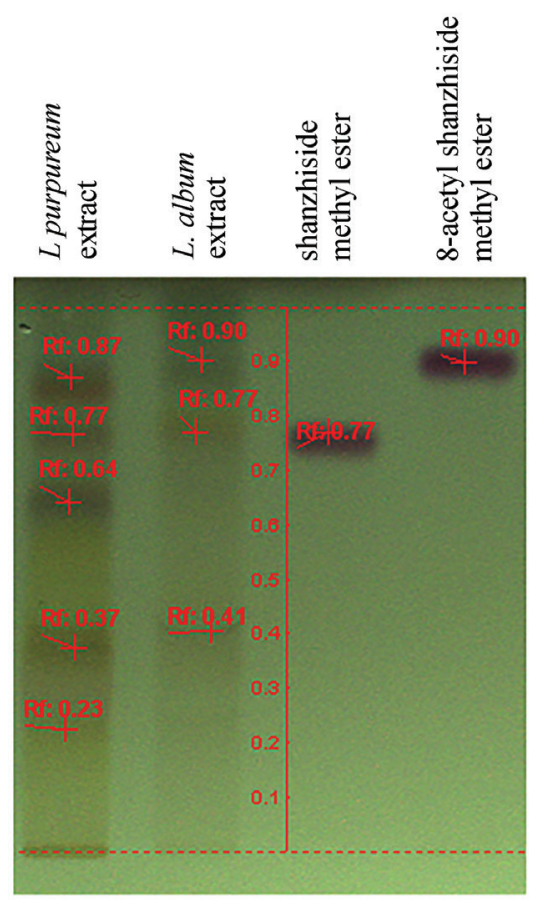

Fig. 1. TL chromatograms of butanol extracts of Lamium purpureum and Lamium album aerial parts. 
C. Bubueanu et al.: Haemostatic activity of butanolic extracts of Lamium album and Lamium purpureum aerial parts, Acta Pharm. 69 (2019) 443-449.
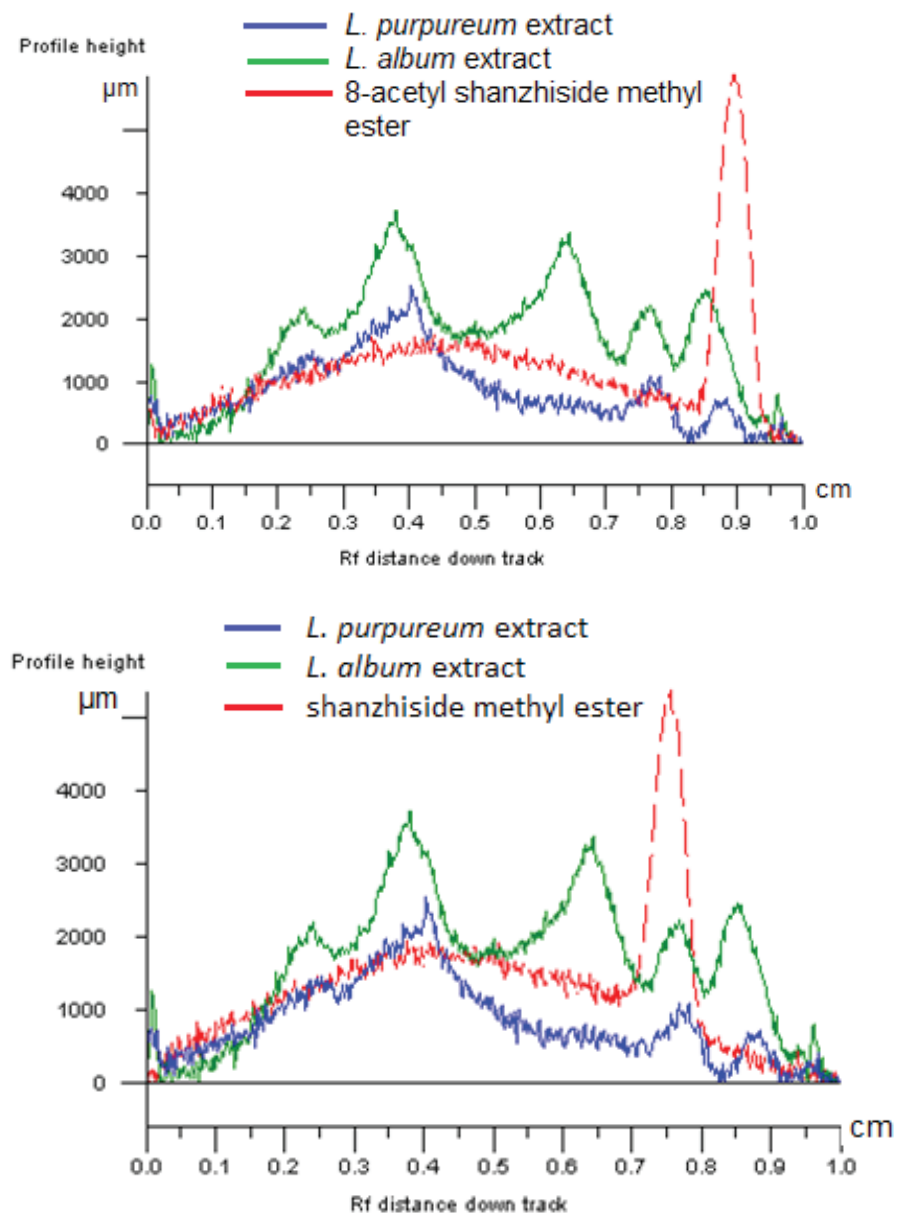

Fig. 2. Comparison between butanol extracts of Lamium purpureum and Lamium album aerial parts, and a) 8-acetyl shanzhiside methyl ester, and b) shanzhiside methyl ester (reference substance) fingerprints.

8-acetyl shanzhiside methyl ester (Figs. 2a,b). Shanzhiside methyl ester $\left(R_{\mathrm{f}} \sim 0.77\right)$ and 8 -acetyl shanzhiside methyl ester $\left(R_{\mathrm{f}} \sim 0.90\right)$ were preliminarily identified in Lamium album extract. In Lamium purpureum extracts only shanzhiside methyl ester was detected (Fig. 1).

\section{Acute toxicity test}

In the 14 days of the experiment, no signs of toxicity were recorded, nor any changes in spontaneous behaviour or in the appearance of animals. No deaths were recorded either. Macroscopic examination did not reveal any pathological modification of parenchymal organs, serous cavities or abnormal blood distribution. Thus, the tested extracts exerted no toxicity after a single $7.0 \mathrm{mg} \mathrm{kg}^{-1}$ oral dose. 


\section{Haemostatic test by tail bleeding time determination}

Both tested extracts showed a decrease in bleeding time compared to the control (223.3 s): Lamium album extract with a medium bleeding time of $71.3 \mathrm{~s}$ (32\% of the control) and Lamium purpureum extract with $115 \mathrm{~s}$ (51 \% of the control).

\section{Acenocoumarol-carrageenan test}

In this experiment, performed to reveal the influence of the tested extracts upon a haematoma induced by subcutaneous injection of carrageenan into the top of the rat skull during oral treatment with acenocoumarol, the following was noticed.

Administration of $1.35 \mathrm{mg} \mathrm{kg}^{-1} \mathrm{bm}$ vitamin $\mathrm{K}$ per os before administration of the phlogistic agent (carrageenan) and followed by daily treatment with acenocoumarol for 3 days caused no haematoma at the carrageenan injection site. Preventive action of $10 \%$ Lamium album extract was observed. Presumptive haematoma prevention index of $83 \%$ for males and $67 \%$ for females, compared to the preventive activity of vitamin $\mathrm{K}$ as $100 \%$, was calculated.

The present study demonstrates the haemostatic activity of Lamium album extract only. Since 8-acetyl shanzshiside methyl ester was detected only in the Lamium album extract, it might be assumed as being responsible for this activity. This is in line with the research on Lamiophlomis rotata (Benth.) Kudo (LR), a plant species used in Chinese traditional medicine for haemostatic and pain relief effects (14). An extract of this species that contained iridoid glycosides showed satisfactory dose-dependent haemostatic activity, the major compounds of the extract being 8-dehydroxy shanzhiside, phloyoside II, shanzhiside methyl ester, loganin and 8-O-acetylshanzhiside methyl ester (by RP-HPLC) (14). Studies of this plant have also shown haemostatic properties of 8-O-acetylshanzhiside methyl ester in capillary coagulation tests and eye haemorrhage tests by significantly shortening the clotting time (15).

\section{CONCLUSIONS}

The obtained results confirm the traditional use of aerial parts of Lamium album for haemostatic activity, which makes it applicable in phytotherapeutic preparations of low/ no toxicity.

Acknowledgements. - The results are protected by the patent No. 129065/30.12.2013 (Romania).

\section{REFERENCES}

1. N. Ito, R. Kakuda, Y. Yaoita and M. Kikuchi, Five new phenylethanoid glycosides from the whole plants of Lamium purpureum L., Chem. Pharm. Bull. 54 (2006) 1705-1708; https://doi.org/10.1248/ cpb.54.1705

2 F. N. Yalçın and D. Kaya, Ethnobotany, pharmacology and phytochemistry of the genus Lamium (Lamiaceae), FABAD J. Pharm. Sci. 31 (2006) 43-52.

3 Z. P. Yordanova, M. K. Zhiponova, E. T. Iakimova, M. A. Dimitrova and V. M. Kapchina-Toteva, Revealing the reviving secret of the white dead nettle (Lamium album L.), Phytochem. Rev. 13 (2014) 375-389; https://doi.org/10.1007/s11101-014-9356-24 
4. R. Paduch, G. Matysik, M. Wójciak-Kosior, M. Kandefer-Szerszeń, A. Skalska-Kamińska, M. Nowak-Kryska and P. Niedziela, Lamium album extracts express free radical scavenging and cytotoxic activities, Polish J. Environ. Stud. 17 (2008) 569-580.

5. S. Damtoft, Iridoid glucosides from Lamium album, Phytochemistry 31 (1992) 175-178; https://doi. org/10.1016/0031-9422(91)83030-O

6. V. Hodisan, T. Perseca and E. Muica, Study on aminoacids from Lamium album L. (Lamiaceae family), Clujul Med. 52 (1979) 361-365.

7. G. Flamini, P. L. Cioni and I. Morelli, Composition of the essential oils and in vivo emission of volatiles of four Lamium species from Italy: L. purpureum, L. hybridum, L. bifidum and L. amplexicaule, Food Chem. 91 (2005) 63-68; https://doi.org/10.1016/J.FOODCHEM.2004.05.047

8. A. Et Sattar, N. Handgieva and S. Popov, Volatile constituents from Lamium maculatum leaves and Nepeta mushrum roots, Dokl. Bulg. Akad. Nauk 46 (1993) 37-39.

9. C. Bubueanu, G. Campeanu, L. Pirvu and G. Bubueanu, Antioxidant activity of butanolic extracts of Romanian native species - Lamium album and Lamium purpureum, Rom. Biotechnol. Lett. 18 (2013) 8855-8862.

10. H. Wagner and S. Bladt, Plant Drug Analysis. A Thin Layer Chromatography Atlas, $2^{\text {nd }}$ ed, SpringerVerlag, Berlin-Heidelberg 1996, pp. 88-90.

11. K. Greene, A. Schiviz, W. Hoellriegl, M. Poncz and E.-M. Muchitsch, Towards a standardization of the murine tail bleeding model, J. Thromb. Haemostasis 8 (2010) 2820-2822; https://doi.org/10.1111/ j.1538-7836.2010.04084.x

12. M. Gábor and Z. Rázga, The acenocoumarol-carrageenin test, Acta Physiol. Hung. 75 (1990) 337342.

13. R. Aiyalu, K. Muthuswamy and A. Ganesan, Haemostatic effect of fresh juice and methanolic extract of Eupatorium ayapana leaves in rat model, Int. J. Biol. Med. Res. 1 (2010) 85-87.

14. M. Li, R. Zhang, Z. Jia, J. Sheng, J. Qiu and J. Wang, Isolation and identification of hemostatic ingredients from Lamiophlomis rotata (Benth.) Kudo, Phytother. Res. 23 (2009) 816-822; https://doi. org/10.1002/ptr.2669

15. P. C. Fan, H. P. Ma, Y. Hao, X. R. He, A. J. Sun, W. Jiang, M. X. Li, L. L. Jing, L. He, J. Ma and Z. P. Jia, A new anti-fibrinolytic hemostatic compound 8-O-acetyl shanzhiside methylester extracted from Lamiophlomis rotata, J. Ethnopharmacol. 187 (2016) 232-238; https://doi.org/10.1016/j. jep.2016.04.016 